\title{
Perceived Adequacy of Illumination, Spatial Brightness, Horizontal Illuminance and Mean Room Surface Exitance in a Small Office
}

James Duff

Technological University Dublin, james.duff@arup.com

Kevin Kelly

Technological University Dublin, kevin.kelly@tudublin.ie

christopher Cuttle

Havelock North, New Zealand.

Follow this and additional works at: https://arrow.tudublin.ie/engscheleart2

Part of the Electrical and Electronics Commons

\section{Recommended Citation}

Duff, J., Kelly, J. \& Cuttle, C. (2015) Perceived Adequacy of Illumination, Spatial Brightness, Horizontal Illuminance and Mean Room Surface Exitance in a Small Office, Lighting Research and Technology, 49(2) . September 2015 DOI: 10.1177/1477153515599189

This Article is brought to you for free and open access by the School of Electrical and Electronic Engineering at ARROW@TU Dublin. It has been accepted for inclusion in Articles by an authorized administrator of ARROW@TU Dublin. For more information, please contact arrow.admin@tudublin.ie, aisling.coyne@tudublin.ie, gerard.connolly@tudublin.ie.

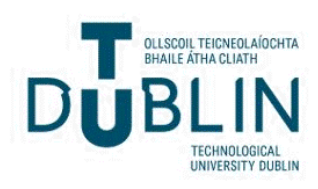




\title{
Perceived adequacy of illumination, spatial brightness, horizontal illuminance and mean room surface exitance in a small office
}

\section{JT Duff BSc, ${ }^{\mathrm{a}}$ K Kelly EdD ${ }^{\mathrm{b}}$ and C Cuttle MA ${ }^{\mathrm{c}}$}

\author{
${ }^{a}$ Arup Lighting and Dublin Institute of Technology, Dublin, Ireland \\ ${ }^{\mathrm{b}}$ Dublin Institute of Technology, Dublin, Ireland. \\ ${ }^{\mathrm{c}}$ Havelock North, New Zealand.
}

Short title: Perceived adequacy, brightness, horizontal illuminance and MRSE

Received 13 June 2015; Revised 10 July 2015; Accepted

This paper presents a pilot study that investigated the suitability of mean room surface exitance as a predictor of spatial brightness and perceived adequacy of illumination, then compared these results with how horizontal illuminance predicted both items under the same conditions. An experiment used 26 participants and a small office. It exposed participants to three levels of mean room surface exitance, each delivered with three different light distributions and across three different surface reflectances, resulting in a total of 27 light scenes. A clear relationship existed between mean room surface exitance and both perceived adequacy of illumination and spatial brightness, but not between horizontal illuminance and either item. Correlations were drawn between reported levels of spatial brightness and reported levels of perceived adequacy of illumination.

Address for Correspondence: James Duff, Ove Arup and Partners Ltd, 50 Ringsend Road, Dublin 4, Ireland.

E-mail: james.duff@arup.com 


\section{Introduction}

Current indoor lighting guidance documents recommend a range of criteria that designers must satisfy to ensure compliance. ${ }^{1-3}$ Recent revisions of European standards have included a number of changes and additional metrics; most notable amongst these being the introduction of a required minimum quantity of illuminance on major room surfaces, mean cylindrical illuminance and a modelling index; each respectively stated to aid room brightness, to help with visual communication and to ensure appropriate modelling. In addition, guidance documents now advocate that the designer should choose an appropriate working plane, which may, or may not be, the horizontal plane. Whilst the authors recognise that standards and guidance have formally changed, it is still apparent that the most widely applied lighting metric in practice remains the quantity of illuminance measured on a horizontal working plane. $^{4}$

Cuttle has introduced a new methodology for indoor electric lighting design that places emphasis on the appearance of a space and may better relate to what we see. ${ }^{5-9}$ As part of this method, Cuttle has proposed the concept of perceived adequacy of illumination (PAI) for use in lighting standards. ${ }^{7}$ PAI is the quantity of light within a space that is likely to be judged sufficiently bright, or adequate, for the activity carried out in that particular space. It has been suggested that mean room surface exitance (MRSE), ${ }^{6}$ being the measure of overall density of reflected (excluding direct) flux within a space, is a metric that may correlate with the perceived brightness of a space and in turn, PAI. A full explanation of the terms above and some design examples are available elsewhere. ${ }^{5,7,10}$

Spatial brightness is a term that has been used to relate to the perceived brightness of a space. Spatial brightness has also previously been referred to as building lighting, ${ }^{11}$ room brightness $^{12}$ or scene brightness. ${ }^{13,14}$ Many past studies have investigated the influence of spectral power distribution on spatial brightness, ${ }^{15-25}$ Fotios et al provide a useful review. ${ }^{26}$ Other studies have investigated the relationship between spatial brightness and light on a vertical plane ${ }^{27}$ and also luminance within a defined field of view. ${ }^{28,29}$ Rea et al found illuminance on a vertical plane to correlate better with assessments of brightness than that of light on a horizontal plane. ${ }^{27}$ In two separate studies, Loe et al found strong correlations between assessments of brightness and the illumination of a horizontal band $40^{\circ}$ wide. $^{28,29}$ In a previous pilot study that utilised a scaled booth, the authors found MRSE correlated strongly with assessments of spatial brightness. ${ }^{30}$ 
Cuttle’s ideas have generally been well received, ${ }^{31-36}$ but before this procedure can be introduced into standards, the relationship between MRSE and spatial brightness, and in turn, spatial brightness and PAI, must be better understood. In addition, using MRSE in standards must be shown to improve lighting quality when compared with the current situation in practice, this being the widespread use of horizontal working plane illuminance $\left(E_{h}\right)$. This paper investigates the relationships between MRSE and PAI, between MRSE and spatial brightness and finally between spatial brightness and PAI. It also compares how MRSE and $\mathrm{E}_{\mathrm{h}}$ perform as predictors of both PAI and spatial brightness.

\section{Method}

This pilot study used a small room as an experimental space. The room used was $5000 \mathrm{~mm}$ long, $2900 \mathrm{~mm}$ wide and $2850 \mathrm{~mm}$ high. The room contained a single work desk and two chairs and was completely shielded from daylight penetration. Lighting was provided by linear T5 fluorescent luminaires on the ceiling, TC-DEL fluorescent wall uplights and T5 fluorescent freestanding floor lamps, all of which were dimmable. All lamps had a manufacturer stated correlated colour temperature (CCT) of $4000 \mathrm{~K}$ and a general colour rendering index (Ra) of 80. Luminaires were circuited, grouped (SC-1, SC2 and SC-3) and dimmed together to produce uplight and downlight components (Figure 1 and 2). Light scenes were programmed using a DALI or DSI interface and a scene set panel. Ceiling and wall luminaires were connected back to a wall mounted DALI scene set panel. The floor standing luminaires contained in-built DSI scene set options. Reflectance values were calculated using luminance and illuminance measurements. Luminance values were recorded using a Konica Minolta LS-110 luminance meter at $300 \mathrm{~mm}$ intervals across each of the major room surfaces and converted to MRSE using equations 1 and 2. Prior to beginning each experiment, all lamps were run at full light output for a sufficient length of time such that output stabilised. During the experimental procedure, previously recorded MRSE values were verified with spot measurements taken at the start and end of each light scene.

For each surface within the room, the mean exitance of that surface $\left(\mathrm{M}_{\mathrm{S}}\right)$ is given by the product of the mean recorded luminance $\left(\mathrm{L}_{\mathrm{S}}\right)$ and pi:

$$
M_{S}=L_{S} \pi
$$

The MRSE is then given by the sum of the area-weighted exitance values for all surfaces, divided by the total room surface area: 


$$
M R S E=\frac{\sum M_{S} A_{S}}{\sum A_{S}}
$$

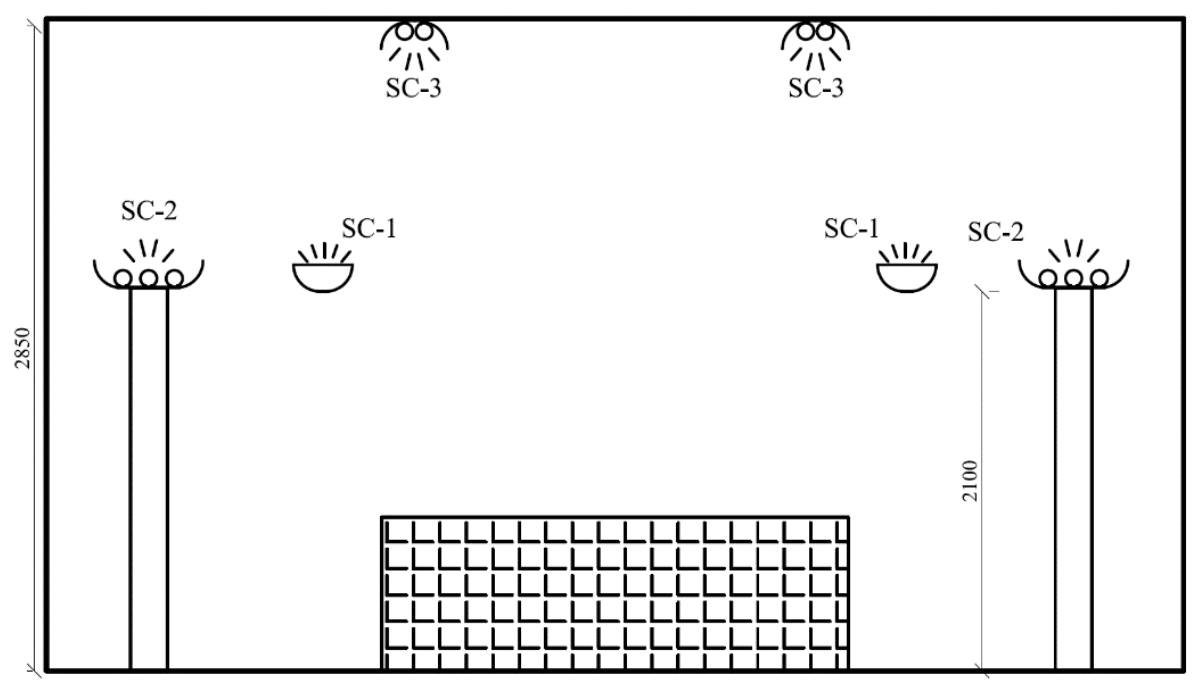

Figure 1. Elevation section of the test space used. Note switching references as laid out in Table 1.

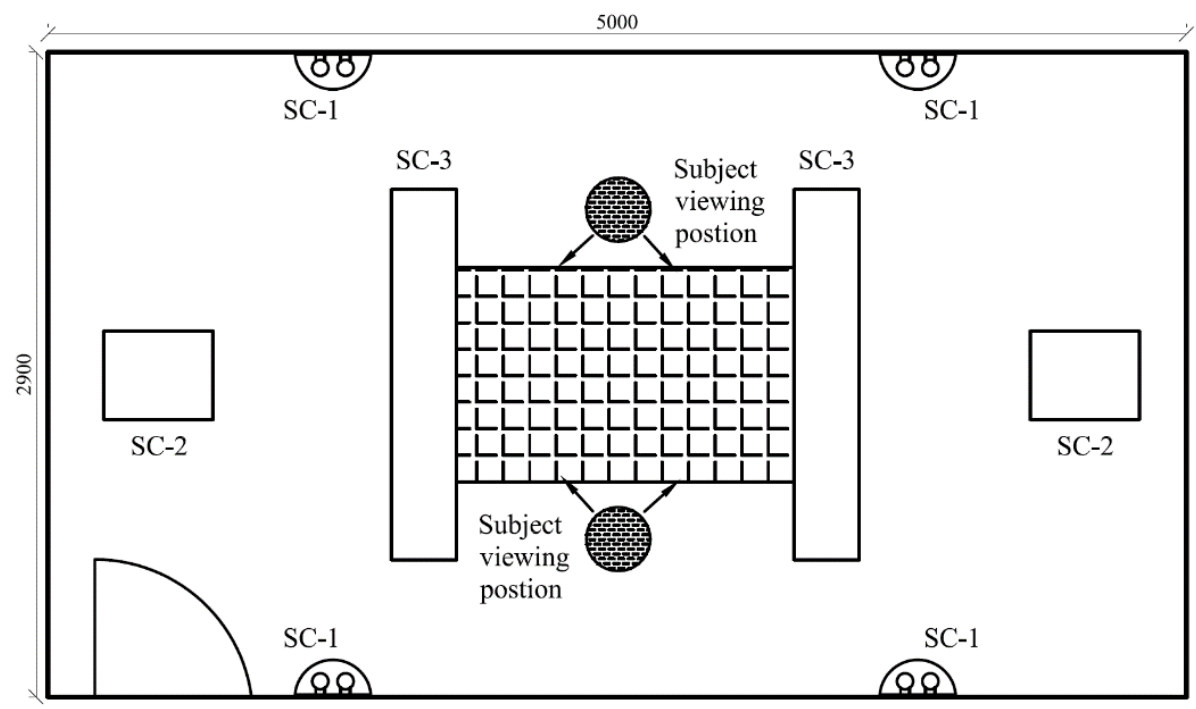

Figure 2. Plan section of the test space used. Note the switching references as laid out in Table 1.

The study examined subjective response to spatial brightness and PAI. The study included 26 participants, aged between 18 and 25 years $($ Mean $=20.8$, standard deviation $=2.3$ ) with no participants using corrective eyewear. In each experiment, participants viewed a range of light scenes. The experiment used groups of two participants and each participant completed three separate sittings. A $300 \mathrm{~mm}$ high partition was placed across the centre of the table and used to prevent one participant viewing the written responses of the other participant. 
During each sitting, participants were exposed to nine different light scenes at varying levels of MRSE, with the corresponding level of $E_{h}$ at workplane level (0.8m AFFL) also recorded. Three levels of MRSE were set up; $25 \mathrm{~lm} / \mathrm{m}^{2}, 50 \mathrm{~lm} / \mathrm{m}^{2}$ and $100 \mathrm{~lm} / \mathrm{m}^{2}$, along with three methods to achieve the distributions of each, these being indirect, direct and mixed. Indirect scenes were a combination of SC-1 and SC-2, direct scenes were solely SC-3 and the mixed scenes were a combination of all three switching circuits. The reflectance of the room surfaces were also varied to broadly represent light, medium and dark surface properties. All of these combinations produced a total of 27 light scenes. A graphical breakdown of the light scenes is given in Figure 3 and further details about surface reflectances, luminance distribution and luminance uniformity are given in Table 1.

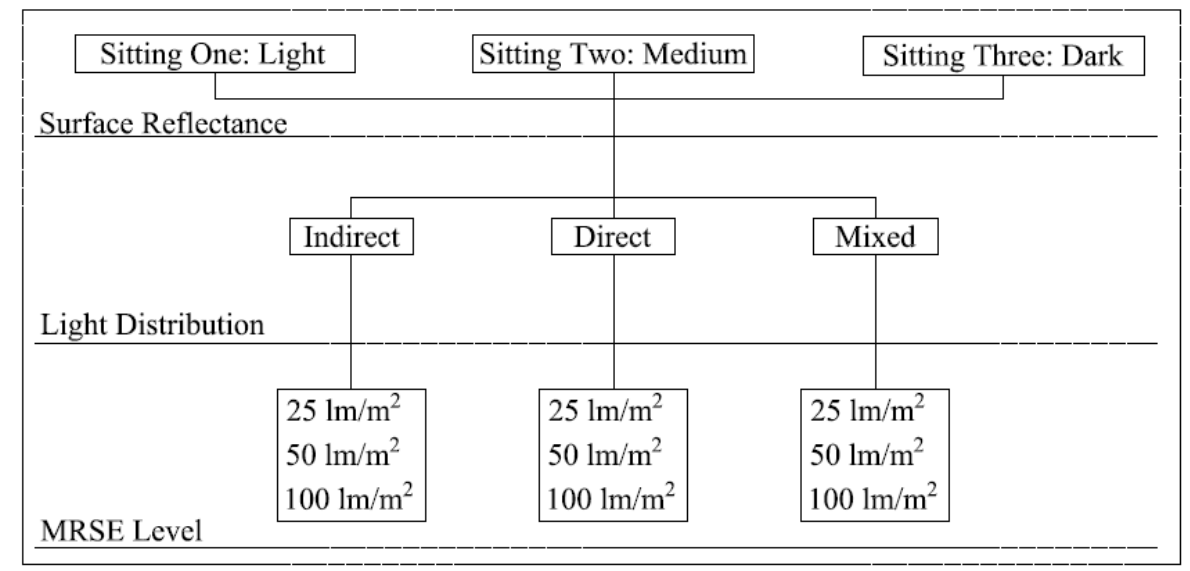

Figure 3. Graphical representation of each light scene presented. Note that each sitting contained fixed surface reflectances, but varied levels of MRSE and light distribution.

The order of exposure to light scenes was randomised and three scenes were repeated to compare participants' responses to identical scenes. This was used to assess if the order of light scene exposure had a significant impact on assessments. The repeated scenes were scene 7, scene 14 and scene 21 and were chosen to best include each of the variables; being one scene from each level of MRSE, one scene from each light distribution and one scene from each surface reflectance. The light scene numbers are given in Table 1. Participants were exposed to each scene for two minutes and during each scene, answered a first question that examined PAI, with a binary response required, in addition to a second question that asked about subjective spatial brightness levels, with responses given on a seven point semantic differential scale. Question response polarity was varied at random to prevent directional bias. 
Q1. The lighting in the space is adequate - Yes / No

Q2. On the scale below, please rate the brightness of the entire space.

\begin{tabular}{l|l|l|l|l|}
$\operatorname{very} \operatorname{dim}$ & $\operatorname{dim}|\operatorname{slightly} \operatorname{dim}|$ neither dim nor bright $\mid \begin{array}{l}\text { slightly } \\
\text { bright }\end{array}$
\end{tabular} \mid bright $\mid$ very bright

Adequate lighting was defined as "the correct quantity of light for use in an office space”. Brightness scales were defined using the definition coined by Vrabel et al; " bright is represented by the light in an outdoor sports area (when all the floodlights are on) and very dim is the level of an outdoor parking lot at night". In addition to this, participants were reminded prior to each scene change that they should relate brightness to the entire space, and not solely their immediate field of view.

\section{Results}

Responses to PAI were assigned values of one for Yes and two for No, with the percentage of participants responding Yes given in results. Values of one to seven were assigned for responses from very dim to very bright respectively. A full list of the percentage of participants that responded Yes and the mean spatial brightness response ratings, coupled with the associated standard deviations for all light scenes is given within Table 1 .

\section{Data analysis}

Using parametric statistical tests requires that data be drawn from a normally distributed sample. Binary data cannot be normally distributed and as such, non-parametric tests were applied. Distribution of brightness response data was investigated using statistical and graphical methods available through SPSS, namely; measures of central tendency, skewness, frequency histogram, kurtosis, box and whisker plots and probability plots. Results of these tests indicated that the data was not normally distributed and as such, non-parametric statistical tests have been applied.

\subsection{Repeated scenes}

Repeated scenes were introduced to ensure that the order of light scene exposure had no impact on subjective assessments. As stated previously, three scenes were repeated without the participants knowledge; scene 7, scene 14 and scene 21, with the repeated scene being excluded from the final results. 
The three binary response scores for PAI were tested in pairs using the McNemar test. All three scenes produced no statistically significant differences between participants' responses when a scene was viewed first or second (scene $7, X^{2}(1)=1.5, p=0.204$; scene $14, X^{2}(1)=0.33, p=0.564$ and scene $\left.21, X^{2}(1)=1.00, p=0.317\right)$. Scores produced from each of the spatial brightness responses were examined using the Wilcoxon signed-rank test. All three scenes repeated produced no statistically significant difference between the participants' first response and their second (scene $7, Z=-1.633, p=0.102$; scene $14, Z=$ 0.707, $p=0.480$ and scene $21, Z=-0.333, p=0.739$ ). It can thus be concluded that the order of exposure had no significant impact on participants' assessments.

\subsection{MRSE and PAI}

Cochran's Q was applied to investigate the influence of the independent variables on assessments of PAI. To change the reflectances of the room surfaces, they were cleaned and repainted. With this being unavoidable, participants then viewed the scenes in three separate sittings (one for each reflectance) but all in the same order, producing an associated order effect. For this reason, three separate Cochran's Q tests were carried out on the data for each level of surface reflectance, but also for each independent variable, these being the level of MRSE (3) and light distribution (3).

In sitting one, participants viewed scenes with light surface reflectances as given in Table 1. Applying Cochran's $Q$ to all the data from sitting one indicated a statistically significant difference between the proportions, $X^{2}(2)=27.25, p=0.001$. Using Cochran's $\mathrm{Q}$ to further analyse the data showed that no significant difference occurred due to light distribution at each level of MRSE (MRSE of 25lm/ $\mathrm{m}^{2}, X^{2}(2)=1.4, p=0.497$; MRSE of $50 \mathrm{~lm} / \mathrm{m}^{2}, X^{2}(2)=0.7, p=0.705$ and MRSE of $100 \mathrm{~lm} / \mathrm{m}^{2}, X^{2}(2)=2.47, p=0.29 I$ ) but statistically significant differences were found within each light distribution type due to the level of MRSE (Indirect, $X^{2}(2)=6.778, p=0.034$; Direct, $X^{2}(2)=6.1, p=0.047$ and Mixed, $\left.X^{2}(2)=8.27, p=0.013\right)$.

In sitting two, participants viewed scenes with medium surface reflectances as given in Table 1. Applying Cochran's Q to all the data from sitting two indicated a statistically significant difference between the proportions, $X^{2}(2)=23.524, p=0.003$. Using Cochran's $\mathrm{Q}$ to further analyse the data showed that no significant difference occurred due to light distribution at each level of MRSE (MRSE of 25lm/ $\mathrm{m}^{2}, X^{2}(2)=0.333, p=0.846$; MRSE of $50 \mathrm{~lm} / \mathrm{m}^{2}, X^{2}(2)=0.5, p=0.779$ and MRSE of $100 \mathrm{~lm} / \mathrm{m}^{2}, X^{2}(2)=0.636, p=0.727$ ). 
Statistically significant differences, due to level of MRSE, were found within the direct and the mixed light distribution types (Direct, $X^{2}(2)=7.385, p=0.025$ and Mixed, $X^{2}(2)=10.0$, $p=0.007$ ), but not within the indirect (Indirect, $\left.X^{2}(2)=5.765, p=0.056\right)$. It can be noted that whilst the indirect scenes did not produce significant differences between levels of MRSE, the value reported is very close to being significant, i.e. $p<0.05$.

In sitting three, participants viewed scenes with dark surface reflectances as given in Table 1. Applying Cochran's $Q$ to all the data from sitting three indicated statistically significant differences between the proportions, $X^{2}(2)=30.227, p<0.001$. Using Cochran's $\mathrm{Q}$ to further analyse the data showed that no significant difference occurred due to light distribution at each level of MRSE (MRSE of 25lm/m $\mathrm{m}^{2}, X^{2}(2)=1.143, p=0.565$; MRSE of $50 \mathrm{~lm} / \mathrm{m}^{2}, X^{2}(2)=0.118, p=0.943$ and MRSE of $100 \mathrm{~lm} / \mathrm{m}^{2}, X^{2}(2)=1.13, p=0.568$ ) but statistically significant differences were found within each light distribution type due to level of MRSE (Indirect, $X^{2}(2)=9.5, p=0.009$; Direct, $X^{2}(2)=8.714, p=0.013$ and Mixed, $\left.X^{2}(2)=9.3, p=0.01\right)$.

\subsection{MRSE and spatial brightness}

Repeated measures analysis of variance (ANOVA) was used to investigate the influence of the different independent variables on spatial brightness assessments. Again, and for the reasons described previously, an order effect existed such that results had to be analysed separately for each level of surface reflectance presented. As such, three separate two by three repeated measures ANOVA's were carried out, with level of MRSE (3) and light distribution (3) as the independent variables.

In sitting one, participants viewed scenes with light surface reflectances as given in Table 1. Mauchly's test of sphericity demonstrated that for these results, sphericity could be assumed for light distribution, $X^{2}(2)=0.555, p=0.758$, level of MRSE, $X^{2}(2)=2.637, p=$ 0.268 , and the interaction between level of MRSE and light distribution, $X^{2}(9)=5.425, p=$ 0.796. Within subjects effects then showed that subjective assessment of spatial brightness was influenced by level of MRSE, $F(2,50)=190.32, p<0.001$, and also by light distribution, $F(2,50)=36.57, p<0.001$. There was no statistically significant interaction between level of MRSE and light distribution, $F(4,100)=0.438, p=0.78$.

Post-hoc paired comparisons, using a Bonferroni correction, were made to examine which pairs of means differed. For light distribution, there was a significant difference 
between each of the pairs of means $(p<0.001)$. For level of MRSE, there was also a statistically significant difference between each of the pairs of means $(p<0.001)$.

In sitting two, participants viewed scenes with medium surface reflectances as given in Table 1. Mauchly's test of sphericity demonstrated that for these results, sphericity could be assumed for light distribution, $X^{2}(2)=2.506, p=0.268$, level of MRSE, $X^{2}(2)=2.239, p$ $=0.312$, and the interaction between level of MRSE and light distribution, $X^{2}(9)=15.156, p$ $=0.087$. Within subjects effects showed that subjective assessment of spatial brightness was influenced by level of MRSE, $F(2,50)=256.272, p<0.001$, and also by light distribution, $F(2,50)=17.755, p<0.001$. There was no statistically significant interaction between level of MRSE and light distribution, $F(4,100)=0.327, p=0.859$.

Post-hoc paired comparisons, using a Bonferroni correction, were made to examine which pairs of means differed. For light distribution, there was again a significant difference between direct and indirect scenes $(p<0.001)$, between direct and mixed $(p<0.001)$ and also between the mixed and indirect scenes $(p=0.004)$. For level of MRSE, there was again a statistically significant difference between each of the pairs of means $(p<0.001)$

In sitting three, participants viewed scenes with dark surface reflectances as given in Table 1. Mauchly's test of sphericity demonstrated that for these results, sphericity could be assumed for light distribution, $X^{2}(2)=1.034, p=0.596$, level of MRSE, $X^{2}(2)=4.841, p=$ 0.089 , and the interaction between level of MRSE and light distribution, $X^{2}(9)=8.83, p=$ 0.847. Within subjects effects then showed that subjective assessment of brightness was influenced by level of MRSE, $F(2,50)=262.65, p<0.001$, and also by light distribution, $F(2,50)=30.714, p<0.001$. There was no statistically significant interaction between level of MRSE and light distribution, $F(4,100)=0.866, p=0.487$.

Post-hoc paired comparisons, using a Bonferroni correction, were made to examine which pairs of means differed. For light distribution, there was again a significant difference between direct and indirect scenes $(p=0.003)$, between direct and mixed $(p<0.001)$ and also between the mixed and indirect scenes $(p=0.003)$. For level of MRSE, there was a statistically significant difference between each of the pairs of means $(p<0.001)$.

\subsection{Spatial brightness and PAI}

Applying a Perason product-moment correlation to both the percentage of Yes responses to PAI and the mean spatial brightness response score produced a strong 
correlation between the two items $(r=0.95, n=27, p<0.001)$. A scatterplot in Figure 4 summarises the data.

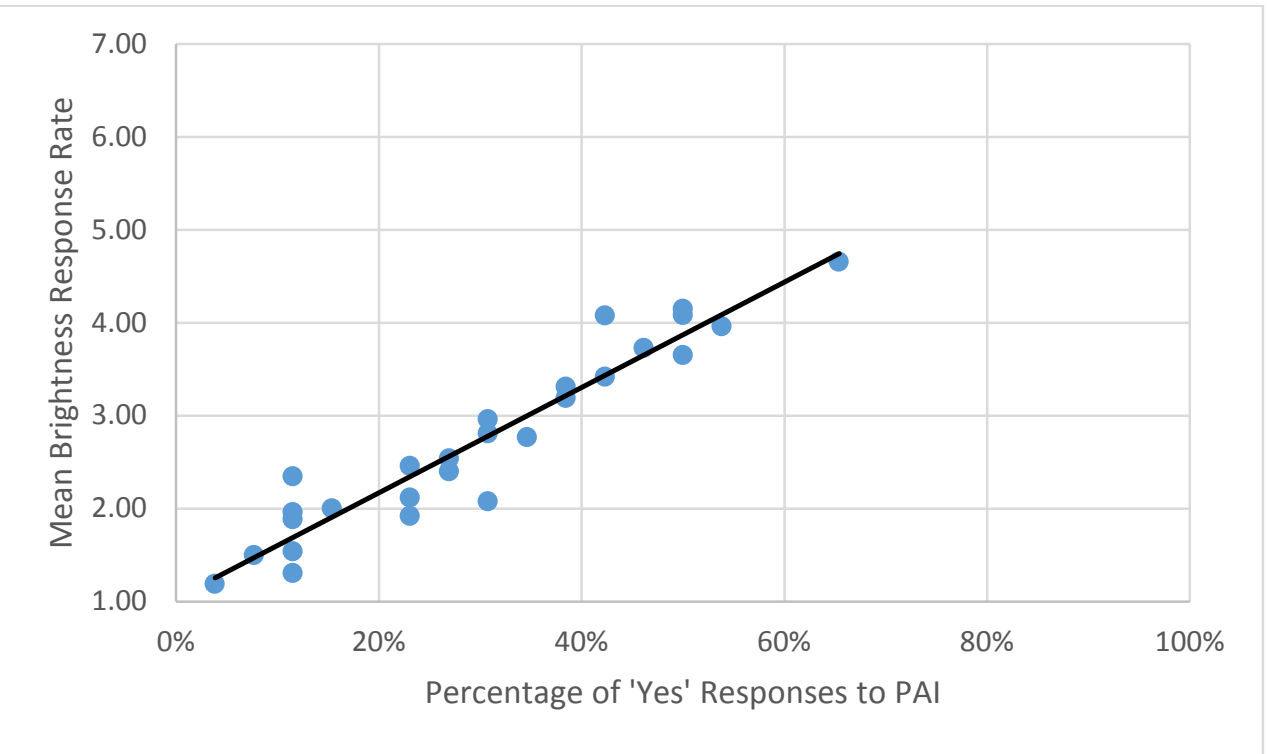

Figure 4. The correlation found between mean ratings of spatial brightness and levels of perceived adequacy of illumination.

\subsection{MRSE and mean horizontal illuminance}

Plotting the percentage of Yes responses to PAI for each light scene visually indicates the relationship between MRSE and PAI, compared with $\mathrm{E}_{\mathrm{h}}$ and PAI (Figures 5 and 6). Applying a linear regression model to the level of MRSE and the proportion of Yes PAI responses produces a noticeable relationship between the two variables $\left(R^{2}=0.81\right)$. Within this experiment, horizontal illuminance was not explicitly controlled as an independent variable and participants were generally exposed to a somewhat small range of values, typically between 50 lux and 250 lux. However, applying a linear regression model to $\mathrm{E}_{\mathrm{h}}$ and PAI serves as a useful backward inference as to the relationship experienced between the two items. Modelling the data set as a whole produces no predictable relationship between the two items $\left(R^{2}=0.19\right)$. It can be seen from Figure 6 that three outlying points strongly influenced the regression line. Running the linear regression model and excluding these three points improves the coefficient of determination $\left(R^{2}=0.56\right)$. 


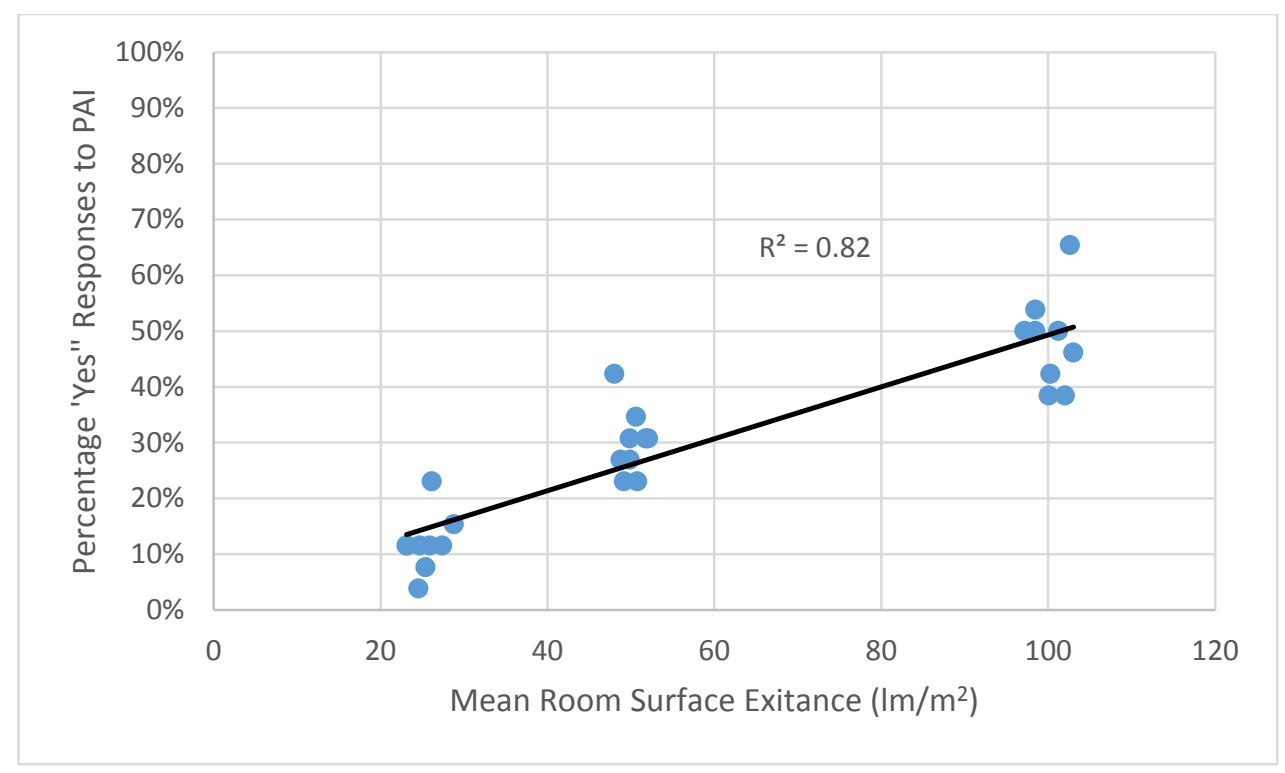

Figure 5. The percentage of Yes responses to perceived adequacy of illumination plotted against the mean room surface exitance for each light scene presented.

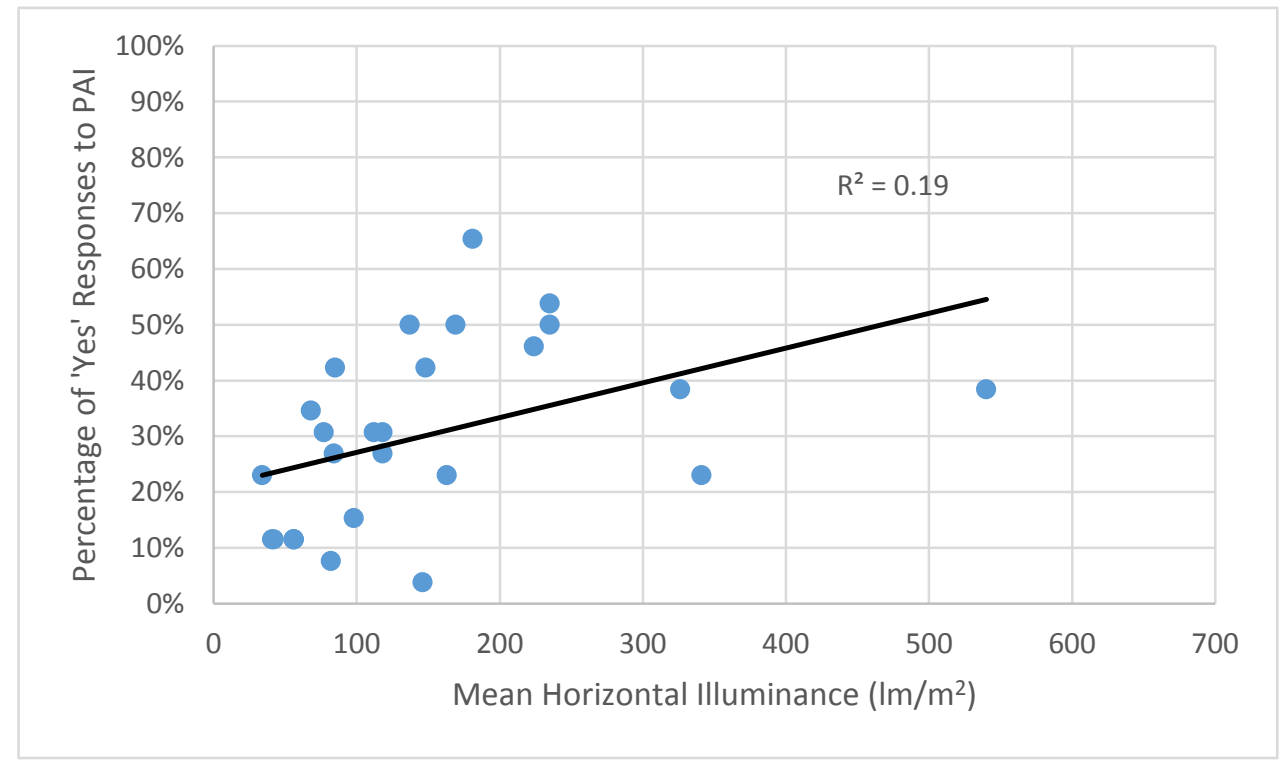

Figure 6. The percentage of Yes responses to perceived adequacy of illumination plotted against the mean horizontal illuminance for each light scene presented.

Applying the same procedure to the mean spatial brightness response of each light scene visually demonstrates the difference in relationship between MRSE and spatial brightness, compared with $\mathrm{E}_{\mathrm{h}}$ and spatial brightness (Figure 7 and 8). Applying a linear regression to MRSE and spatial brightness produces a strong relationship between the two 
items $\left(R^{2}=0.79\right)$. Applying a linear regression model to $\mathrm{E}_{\mathrm{h}}$ and spatial brightness indicates no clear relationship between the two items $\left(R^{2}=0.14\right)$. From viewing Figure 8, it can be seen that three points within this data set strongly influenced the regression line, so the model was re-run without these points, improving the coefficient of determination $\left(R^{2}=0.39\right)$.

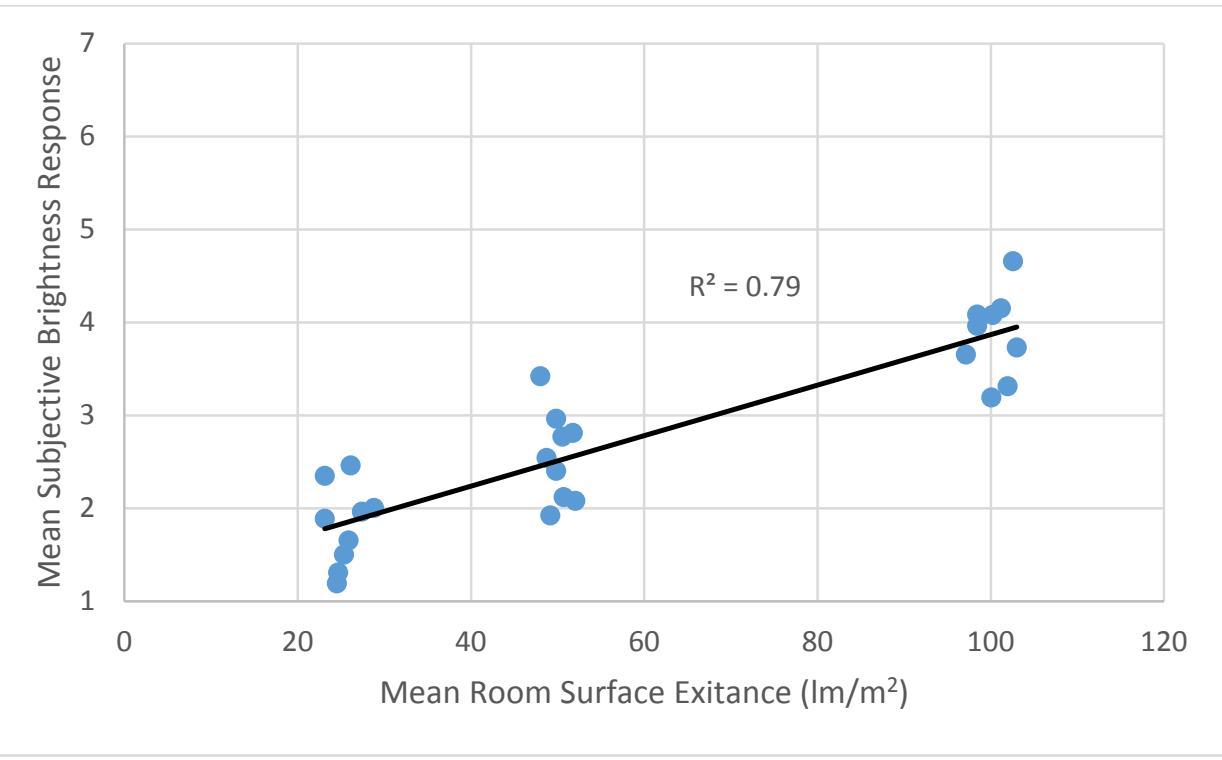

Figure 7. The mean spatial brightness rating plotted against the mean room surface exitance for each light scene presented.

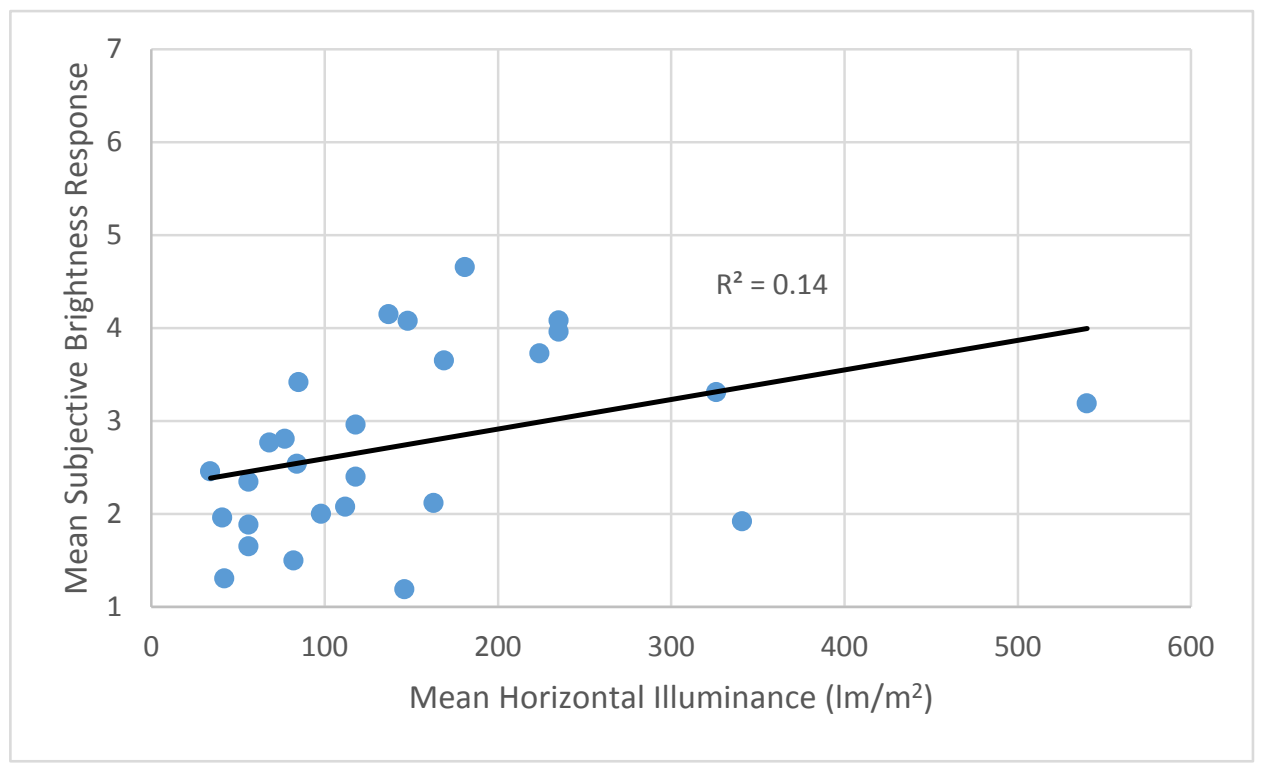

Figure 8. The mean spatial brightness rating plotted against the mean horizontal illuminance for each light scene presented. 


\section{Discussion}

Statistical testing showed that regardless of light distribution or surface reflectance, in the light scenes presented, the level of MRSE had a significant impact on subjective assessment of both PAI and spatial brightness. Participants were exposed to two independent variables during each sitting, MRSE and light distribution, however, the analysis demonstrated that the level of MRSE had a stronger impact on assessment on both PAI and spatial brightness than did light distribution.

The relationship between luminance and brightness has previously been shown to be logarithmic ${ }^{38-42}$ but the upper levels of luminance used in these experiments was far in excess of what participants in the current study were exposed to. Previous work by the authors mimicked the experimental process of the current study, but utilised a scaled booth to make assessments of spatial brightness. This work found a linear relationship between reported levels of spatial brightness and MRSE of the form shown in equation 3. Results found in this study could be considered close enough to tentatively reinforce these findings. Remembering that values one to seven were assigned to each response category from very dim to very bright, the relationship between spatial brightness $(B)$ and MRSE experienced in this study can be approximately summated by:

$$
B=1+\frac{M R S E}{30}
$$

However, and as stated in the authors previous work, it should be noted that the maximum value of MRSE used was $100 \mathrm{~lm} / \mathrm{m}^{2}$. The authors still envisage that as levels of MRSE increase above this value, ratings of brightness may plateau, perhaps producing the expected logarithmic relationship. Further understanding of this relationship will be a focus for future work.

The concept of PAI very much relies on the premise that people will relate levels of spatial brightness to the feeling of the lighting in a space being appropriate. In the study presented, participants related levels of MRSE to spatial brightness and also related levels of MRSE to PAI. With MRSE being so closely linked to both items, correlations could be drawn between both of the dependant variables. Figure 4 graphically indicates the strong correlation that existed between spatial brightness and PAI for the particular light scenes presented in this study. 
From both the linear regression analyses results, and visually from Figures 5 to 8, it can be seen that for the light scenes used in this study, MRSE was a more accurate predictor of both PAI and spatial brightness than $\mathrm{E}_{\mathrm{h}}$. Logically, increasing or decreasing the luminance of the surfaces within a space will have an impact on how dim or bright it appears, but the illumination engineering metrics used to control this phenomena are not yet widely understood. In addition, there is a lesser understanding of how perceived levels of brightness relate to human satisfaction within general interior environments. Loe et al investigated subjective response to number of items, ${ }^{29}$ one of which was brightness, within a range of light scenes in an illuminated interior. They used the average luminance and the luminance distribution standard deviation within a horizontal, $40^{\circ}$ wide band to try and assess the lit environment and found strong correlations between the mean luminance in the $40^{\circ}$ wide band and subjective response to brightness. The authors here did not record luminance values within the horizontal $40^{\circ}$ wide band, but did record luminance values on each of the room walls. Using the premise that the mean luminance of the walls is approximately equivalent to that of the $40^{\circ}$ wide band, correlations can be drawn between mean wall luminance and $\operatorname{MRSE}(r=0.92)$ and also between mean wall luminance and $\mathrm{E}_{\mathrm{h}}(r=0.61)$. This serves to highlight that if controlling luminance in the field of view is of importance, then for the scenes used in this study, MRSE did a better job than $E_{h}$. Additionally, Loe et $\mathrm{al}^{28,29}$ found that firstly, for a room to appear "light", it needed to have an average luminance within the horizontal, $40^{\circ}$ wide band of at least $30 \mathrm{~cd} / \mathrm{m}^{2}$ and secondly, that for a space to "begin to appear bright”, luminance levels within the horizontal $40^{\circ}$ wide band need to be approximately $40 \mathrm{~cd} / \mathrm{m}^{2}$. The authors have previously produced results with similar conclusions $^{30}$ and the results from this study show substantial agreement with previous findings.

\section{Limitations}

The definition of brightness given by the authors to experiment participants should be noted.

This was taken from previous work by Vrabel et $a l^{37}$ and it informed participants to relate very bright to "the light in an outdoor sports area (when all the floodlights are on)" and relate very dim to the brightness "of an outdoor parking lot at night". Whilst defining the ends of the semantic scale has benefits, in this case the chosen definition caused scale compression. None of the light scenes that participants viewed approached a brightness close 
to the level of an outdoor sports area, nor did they come close to the dimness of an outdoor parking lot at night. Defining these extremes may have ultimately inferred to participants that they should not choose towards the outer ends of the scale and the results of this are evident in the brightness levels reported, where few scenes were scored towards the upper end of the brightness scale.

This study presented a range of surface reflectances, but due to the manner in which they were changed, participants viewed them in the same order, thus producing an associated order effect. For this reason, results could not be explicitly compared across each of the levels of surface reflectance.

While this study has examined a number of light distributions, it has not explored extreme distributions. Truly non-uniform distributions were not investigated and it still remains unclear how participants will react to these.

Many past studies have investigated how spectral power distribution affects the perceived brightness of a space and this work is still on-going. The work presented in this paper did not vary spectral power distribution, with each of the sources used having a CCT of $4000 \mathrm{~K}$ and a Ra of 80.

\section{Conclusion}

This paper presented a pilot study conducted as part of on-going research. Within a small office space, it varied level of MRSE, light distribution and surface reflectance to investigate the relationships between MRSE and PAI, between MRSE and spatial brightness and finally between spatial brightness and PAI. It also compared how MRSE and $\mathrm{E}_{\mathrm{h}}$ perform as predictors of both PAI and spatial brightness. From the results and analysis, and giving due consideration to the limitations discussed, the key findings of this study are:

- A simple linear relationship was found to exist between level of MRSE and both PAI and spatial brightness.

- A broadly unpredictable relationship was found to exist between level of $E_{h}$ and both PAI and spatial brightness. 
- Levels of spatial brightness reported were strongly correlated with levels of PAI reported.

These conclusions are drawn by the authors with full acknowledgement that the study conducted is a preliminary study. Further work is underway to continue investigating the topic, with a particular focus on refining the methods used and further examining how more extreme changes in luminous distribution influence assessments of PAI.

\section{Funding}

The author(s) received no financial support for the research, authorship, and/or publication of this article.

\section{References}

1. Society of Light and Lighting. The SLL Code for Lighting. London: SLL, 2009

2. Illuminating Engineering Society of North America, The IESNA Lighting Handbook, 10th Edition, New York: IESNA.

3. Committee of European Standards. EN 12464-1:2011. Light and Lighting - Lighting of workplaces. Part 1: Indoor Workplaces. London: CEN, 2011.

4. Boyce, P.R., Lighting Quality for All? Proceedings of the SLL International Lighting Conference, Dublin, April 2013.

5. Cuttle C. Lighting by Design, 2nd edition, Oxford: Architectural Press, 2008.

6. Cuttle C. Towards the third stage of the lighting profession. Lighting Research and Technology, March 2010; vol. 42(1): 73-93.

7. Cuttle C. A new direction for general lighting practice. Lighting Research and Technology, February 2013; vol. 45(1): 22-39.

8. Cuttle, C. Introduction to a novel perception-based approach to lighting design.

Proceedings of the 4th Professional Lighting Design Convention, Copenhagen, 2013. 152-154.

9. Cuttle C. Lighting Design: A perception-based approach. Oxford: Routledge; 2015. 
10. Duff JT and Kelly K. A new approach to interior lighting design: Early stage research in Ireland. Journal of Sustainable Engineering Design: Vol. 1: Iss. 4. 13-19.

11. Loe D. Measuring the lit appearance of a space. Light and Lighting. 1999, 11: 35-37.

12. Society of Light \& Lighting. 2002. Code for Lighting. Oxford (UK): ButterworthHeinemann.

13. Bullough JD. Spectral sensitivity modelling and nighttime scene brightness perception. Leukos. 2015. vol. 11(1): 11-17.

14. Bullough JD, Radetsky L and Basenecker U. Influence of spectral power distribution on scene brightness at different light levels. Leukos. 2014. 10(1): 3-9.

15. Boyce PR. Investigations of the subjective balance between illuminance and lamp colour properties. Lighting Research and Technology 1977; 9: 11-24.

16. Fotios SA, Levermore GJ. The perception of electric light sources of different colour properties. Lighting Research and Technology 1997; 29: 161-171.

17. Hu X, Houser KW, Tiller DK. Higher colour temperature lamps may not appear brighter. Leukos 2006; 3: 69-81.

18. Alman DH. Errors of the standard photometric system when measuring the brightness of general illumination light sources. Journal of the Illuminating Engineering Society 1977; 6:55-62.

19. Ju J, Chen D, Lin Y. Effects of correlated color temperature on spatial brightness perception. Color Research and Application 2012; 37:450-454.

20. Harrington RE. Effect of color temperature on apparent brightness. Journal of the Optical Society of America 1954; 44: 113-116.

21. Levermore GJ. Perception of lighting and brightness from HID light sources. Lighting Research and Technology 1994; 26: 145-150.

22. Berman SM, Jewett DL, Fein G, Saika G, Ashford F. Photopic luminance does not always predict perceived room brightness. Lighting Research and Technology 1990; 22:37-41.

23. Rea MS. New Benefit Metrics for More Valuable Lighting. Journal of Light \& Visual Environment 2013, doi: IEIJ130000498. 
24. Rea MS. Value Metrics for Better Lighting. Washington: SPIE Press, 2013.

25. Fotios S, Atli D, Cheal C, Hara N. Lamp spectrum and spatial brightness at photopic levels: Investigating prediction using S/P ratio and gamut area. Lighting Research and Technology 2014, doi:10.1177/1477153514546784.

26. Fotios S, Atli D, Cheal C, Houser K and Logadóttir Á. Lamp spectrum and spatial brightness at photopic levels: A basis for developing a metric. Lighting Research and Technology. 2013; 47(3): 80-102.

27. Rea MS, Mou X and Bullogh JD. Scene brightness of illuminated interiors. Lighting Research and Technology. First published 21 April 2015.

doi:10.1177/1477153515581412.

28. Loe DL, Mansfield KP, and Rowlands E. Appearance of the lit environment and its relevance in lighting design: experimental study. Lighting Research and Technology. September 1994; 26(3): 119-133.

29. Loe DL, Mansfield KP, and Rowlands E. A step in quantifying the appearance of a lit scene. Lighting Research and Technology. December 2000; 32(4): 213-222.

30. Duff JT, Cuttle C and Kelly K. Spatial brightness, horizontal illuminance and mean room surface exitance in a lighting booth. Lighting Research and Technology. In Press.

31. Venning B, Poulton K, Shaw K, Loe DL, Raynham P, Hoggett N. Cuttle's Theory, the profession responds. Society of Light and Lighting Newsletter. Vol3, Iss 1. Jan/Feb 2010. 7-9.

32. Macrae I. Comment 1: A new direction for general lighting practice. Lighting Research and Technology, February 2013; vol. 45(1): 22-39.

33. Brandston HM. Comment 3: Towards the third stage of the lighting profession. Lighting Research and Technology, March 2010; vol. 42(1) 73-93.

34. Wilde, MB. Comment 2: A new direction for general lighting practice. Lighting Research and Technology, February 2013; vol. 45(1): 22-39.

35. Bedocs L. Comment 1: Towards the third stage of the lighting profession. Lighting Research and Technology, March 2010; vol. 42(1): 73-93.

36. Mansfield, KP. Comment 2: Towards the third stage of the lighting profession. Lighting Research and Technology, March 2010; vol. 42(1): 73-93. 
37. Vrabel PL, Bernecker CA, Mistrick RG. 1998. Visual performance \& visual clarity under electric light sources: Part II - Visual Clarity. Journal of Illuminating Engineering Soc. 27(1):29-41.

38. Fechner GT. Elementeder Psychopysik. Breitkopf und Hartel, Munich, 1860.

39. Adams QE, Cobb PW. The effect of foveal vision on bright and dark surroundings. The Journal of experimental Psychology, 1992. 5 39-45.

40. Stevens SS. To honour Fechner and repeal his law. Science, 1961. 3446 80-86.

41. Hurvich LM and Jpameson D. Visual scaling. Handbook of Sensory Physiology. 1972, Vol 7 Berlin: Springer.

42. H-W Bodmann and M La Toison. Predicted Brightness - Luminance Phenomena. Lighting Research and Technology. Vol 26 No 3 1994:135-143.

\section{Figure captions}

Figure 1. Elevation section of the test space used. Note switching references as laid out in Table 1.

Figure 2. Plan section of the test space used. Note the switching references as laid out in Table 1.

Figure 3. Graphical representation of each light scene presented. Note that each sitting contained fixed surface reflectances, but varied levels of MRSE and light distribution.

Figure 4. The correlation found between mean ratings of spatial brightness and levels of perceived adequacy of illumination.

Figure 5. The percentage of Yes responses to perceived adequacy of illumination plotted against the mean room surface exitance for each light scene presented.

Figure 6. The percentage of Yes responses to perceived adequacy of illumination plotted against the mean horizontal illuminance for each light scene presented.

Figure 7. The mean spatial brightness rating plotted against the mean room surface exitance for each light scene presented.

Figure 8. The mean spatial brightness rating plotted against the mean horizontal illuminance for each light scene presented. 

Table 1 Properties of the 27 lights scenes examined. Also indicated is the percentage of Yes responses to PAI and the mean subjective spatial brightness rating and associated standard deviation for each light scene.

\begin{tabular}{|c|c|c|c|c|c|c|c|c|c|c|c|}
\hline \multirow[b]{2}{*}{$\begin{array}{c}\text { Light } \\
\text { Scene } \\
\text { Numbe } \\
\text { r }\end{array}$} & \multirow[b]{2}{*}{$\begin{array}{l}\text { Target } \\
\text { MRSE } \\
\left(\mathrm{lm} / \mathrm{m}^{2}\right)\end{array}$} & \multirow{2}{*}{$\begin{array}{c}\text { Surface } \\
\text { Reflectanc } \\
\text { e } \\
\text { (Ceiling/ } \\
\text { Wall/ } \\
\text { Floor) }\end{array}$} & \multirow[b]{2}{*}{$\begin{array}{l}\text { Light } \\
\text { Distribu } \\
\text { tion }\end{array}$} & \multirow[b]{2}{*}{$\begin{array}{l}\text { Recorded } \\
\text { MRSE } \\
\left(\mathrm{lm} / \mathrm{m}^{2}\right)\end{array}$} & \multirow[b]{2}{*}{$\begin{array}{l}\text { Recorded } \\
\text { Horizontal } \\
\text { Illuminanc } \\
\text { e }\left(\mathrm{lm} / \mathrm{m}^{2}\right)\end{array}$} & \multicolumn{4}{|c|}{ Mean Recorded Luminance $\left(\mathrm{U}_{\mathrm{o}}\right),\left(\mathrm{cd} / \mathrm{m}^{2}\right)$} & \multirow{2}{*}{$\begin{array}{c}\text { Q1 } \\
\text { Yes } \\
\text { response } \\
\text { to PAI, } \\
(\%)\end{array}$} & \multirow[b]{2}{*}{$\begin{array}{c}\text { Q2 } \\
\text { Mean Spatial } \\
\text { Brightness } \\
\text { Rating (SD) }\end{array}$} \\
\hline & & & & & & Floor & Ceiling & Long Wall & Short Wall & & \\
\hline 1 & 25 & \multirow{7}{*}{$\begin{array}{l}\text { Sitting } 1 \\
86 / 84 / 24\end{array}$} & Indirect & 29 & 38 & $2.6(0.82)$ & $16.0(0.63)$ & $9.8(0.52)$ & $8.4(0.76)$ & 15.4 & $2.00(0.64)$ \\
\hline 2 & 25 & & Direct & 26 & 98 & $3.8(0.73)$ & $8.0(0.75)$ & $9.3(0.71)$ & $9.5(0.75)$ & 11.5 & $1.65(0.63)$ \\
\hline 3 & 25 & & Mixed & 26 & 56 & $3.7(0.72)$ & $10.1(0.71)$ & $8.9(0.69)$ & $9.2(0.73)$ & 23.1 & $2.46(0.57)$ \\
\hline 6 & 50 & & Mixed & 48 & 85 & $5.8(0.76)$ & $20.0(0.70)$ & $17.0(0.65)$ & $16.0(0.69)$ & 42.3 & $3.42(0.72)$ \\
\hline 7 & 100 & & Indirect & 101 & 137 & $9.2(0.82)$ & $56.0(0.64)$ & $34.0(0.53)$ & $30.0(.63)$ & 50.0 & $4.15(0.58)$ \\
\hline 8 & 100 & & Direct & 103 & 224 & $15(0.73)$ & $32.0(0.75)$ & $\begin{array}{lll}37.0 & 0.70) \\
\end{array}$ & $38.0(0.76)$ & 46.2 & $3.73(0.80)$ \\
\hline 9 & 100 & & Mixed & 103 & 181 & $12(0.77)$ & $44.0(0.70)$ & $36.0(0.64)$ & $34.0(0.71)$ & 65.4 & $4.65(0.75)$ \\
\hline 10 & 25 & \multirow{5}{*}{$\begin{array}{l}\text { Sitting } 2 \\
69 / 62 / 24\end{array}$} & Indirect & 27 & 41 & $2.5(0.79)$ & $19.0(0.52)$ & $8.7(0.42)$ & $6.7(0.59)$ & 11.5 & $1.96(0.59)$ \\
\hline 11 & 25 & & Direct & 25 & 82 & $5.0(0.67)$ & $7.3(0.63)$ & $8.9(0.63)$ & $9.2(0.67)$ & 7.7 & $1.50(0.60)$ \\
\hline 16 & 100 & & Indirect & 100 & 148 & $9.1(0.80)$ & $70.0(0.51)$ & $32.0(0.41)$ & $24.0(0.58)$ & 42.3 & $4.08(0.83)$ \\
\hline 17 & 100 & & Direct & 102 & 326 & $20.0(0.65)$ & $29.0(0.62)$ & $36.0(0.61)$ & $37.0(0.68)$ & 38.5 & $3.31(0.45)$ \\
\hline 18 & 100 & & Mixed & 98 & 235 & $14(0.71)$ & $48.0(0.56)$ & $33.0(0.58)$ & $30.0(0.70)$ & 50.0 & $4.08(0.83)$ \\
\hline 19 & 25 & \multirow{9}{*}{$\begin{array}{l}\text { Sitting } 3 \\
44 / 38 / 17\end{array}$} & Indirect & 25 & 42 & $1.7(0.78)$ & $22.0(0.34)$ & $7.1(0.29)$ & $4.6(0.49)$ & 11.5 & $1.31(0.45)$ \\
\hline 20 & 25 & & Direct & 25 & 146 & $6.0(0.61)$ & $6.0(0.49)$ & $8.5(0.41)$ & $9.0(0.58)$ & 3.8 & $1.19(0.36)$ \\
\hline 21 & 25 & & Mixed & 23 & 56 & $3.5(0.71)$ & $11.0(0.57)$ & $7.7(0.59)$ & $7.1(0.70)$ & 11.5 & $1.88(0.59)$ \\
\hline 22 & 50 & & Indirect & 49 & 84 & $3.5(0.78)$ & $43.0(0.35)$ & $14.0(0.29)$ & $9.2(0.49)$ & 26.9 & $2.54(0.76)$ \\
\hline 23 & 50 & & Direct & 49 & 341 & $12(0.63)$ & $12.0(0.50)$ & $17.0(0.47)$ & $18.0(0.61)$ & $23.1 \%$ & $1.92(0.67)$ \\
\hline 24 & 50 & & Mixed & 50 & 118 & $7.2(0.72)$ & $24.0(0.58)$ & $17.0(0.56)$ & $15.0(0.73)$ & $26.9 \%$ & $2.40(0.69)$ \\
\hline 25 & 100 & & Indirect & 97 & 169 & $7.0(0.78)$ & $94.0(0.35)$ & $28.0(0.29)$ & $18.0(0.50)$ & $50.0 \%$ & $3.65(0.73)$ \\
\hline 26 & 100 & & Direct & 100 & 540 & $34(0.34)$ & $33.0(0.28)$ & $42.0(0.27)$ & $50.0(0.32)$ & $38.5 \%$ & $3.19(0.59)$ \\
\hline 27 & 100 & & Mixed & 98 & 235 & $14.0(0.71)$ & $48.0(0.56)$ & $33.0(0.58)$ & $30.0(0.70)$ & $53.8 \%$ & $3.96(0.52)$ \\
\hline
\end{tabular}


